\title{
O crioulo na poesia caboverdiana da primeira metade do século $\mathrm{xx}$
}

\author{
Maria da Graça Gomes de Pina ${ }^{1}$
}

RESUMO: Neste artigo pretendemos demonstrar o uso do crioulo nos primeiros quartéis do século XX. Para tal, escolhemos alguns casos mais elucidativos e paradigmáticos de seu uso em Cabo Verde, principalmente em poesia. O primeiro poeta a tratar será Eugénio Tavares e o segundo Pedro Cardoso. Consideraremos também, mas muito fugazmente, José Lopes. Estes três escritores foram, de alguma forma, os pioneiros de e para a valorização do crioulo caboverdiano nas primeiras décadas do século passado.

ABSTRACT: This paper wishes to demonstrate the use of the creoles in the first decades of the 20 $0^{\text {th }}$ century. For this purpose we have chosen some paradigmatic cases of the creoles use in Cape Verde, namely in poetry. The first poet will be Eugénio Tavares and the second will be Pedro Cardoso. We will also see José Lopes, but in a very rapid approach. These writers were the pioneers in defending capeverdian creole during the first decades of the $20^{\text {th }}$ century.

PALAVRAS-CHAVE: Tavares; Cardoso; Lopes; crioulo; morna.

KEYWORDS: Tavares; Cardoso; Lopes; creole; morna.

O grande mornista por excelência foi sem dúvida Eugénio Tavares (1867-1930). Acérrimo defensor da utilização da própria língua materna, Tavares foi um dos primeiros escritores a conservar as tradições caboverdianas ao transferir para o papel os costumes e expressões locais da sua gente. Colaborou constantemente em jornais e revistas, dedicando-se de corpo e alma à defesa do seu povo. Escreveu principalmente em língua portuguesa, sobretudo quando pretendia fazer vir à luz problemáticas relacionadas com o escasso interesse da

\footnotetext{
1 Concluiu o Doutoramento em Culture dei Paesi di Lingue Iberiche ed Iberoamericane V ciclo Nuova Serie, pela Università degli Studi di Napoli l" "Orientale", em Abril de 2008 e é actualmente Colaboradora de Língua Portuguesa na Università degli Studi di Napoli "l'Orientale". Email: mgomesdepina@unior.it.
} 
Metrópole pelas ilhas do Cabo Verde e, consequentemente, a má administração dos seus governadores. E não obstante a sua pena tenha descrito para os jornais e revistas (Monteiro 1997; Gomes de Pina 2005) ${ }^{2}$ onde colaborou, temas tão variados como a emigração, o amor, a escolarização, a fome, a seca, etc. (em língua portuguesa), esses mesmos temas foram sabiamente repercorridos em crioulo nas suas mornas poesias dedicadas ao povo caboverdiano. Uma pergunta surge naturalmente desta escolha diferenciada de línguas quanto ao tratamento dos géneros. Por que não utilizar apenas a língua portuguesa? Ou o contrário, por que não utilizar somente o crioulo? As motivações de Tavares são-nos, ou pelo menos assim nos parece, muito claras e justificáveis. Trata-se do destinatário. Para quem escrevia Tavares quando usava a língua portuguesa? Com que propósito? E viceversa. Para tornar mais transparente esta questão, peguemos em dois de seus textos exemplificativos: Pobres da "Revista de Cabo Verde», $\mathrm{n}^{\circ}$ 10, em 1899 (Monteiro 1997: 51) e Despedida: marinheiros que partem da obra Mornas (Tavares 1930: 47-48) São dois casos que podemos considerar convergentes quanto à temática e quanto à utilização da lingua.

a)

Uma pobre mulher, uma viúva com seis filhos, que vendera o pano preto com que envolvia a mágoa da sua saudade no luto pelo marido, - um tísico baleeiro que, estes tempos atrás, viera lá de longe, lá de muito acima do cabo Barrow, na extremidade do norte d'América, a morrer na sua terra sob o olhar manso da mulher e dos filhos; -uma contribuinte que vendera a pequena cruz de prata dum antigo rosário que, talvez nos pudesse contar as dores e os cuidados duma comprida geração de trabalhadores do mar; uma vítima que, ainda com os ombros derreados do peso dessa formidável cruz que se chama - o inventário - já andava a procurar dinheiro para levar ali a um certo onzenário, a um certo judeu que, em sexta-feira santa deste ano da graça de 1899,

\footnotetext{
2 Em Eugénio Tavares pelos jornais..., Monteiro reorganiza quase todas as colaborações de E. Tavares em jornais de Cabo Verde e dos Estados Unidos de América, entre fins do século XIX e primeiros 30 anos do século XX. Através dela podemos aceder a artigos reveladores das condições de vida das colónias portuguesas, com um especial olhar para o arquipélago de Cabo Verde.
} 
andara a citar devedores remissos; uma pobre viúva perguntoume, olhos rasos de água, voz trémula a cortar o coração:

- Já não haverá justiça?

Não respondi. Eu não sabia disso. Não podia informar sobre a existência ou não existência da justiça.

[...]

Eu não via, de há muito, essa deusa. O seu culto limita-se à alma de raro crente. Ter-lhe-iam, porventura, os seus sacerdotes passado o pé... Não respondi, pois, à mulher; o seu olhar, porém, increpando o meu silêncio, fez-me mal.

b)

Es mágua de nha partida el sâ tâ matam nha bida! Se'nbai, ramede ca tem, é'n bai, 'n tornâ bem.

Mas es tristeza de'n bai, de'n bai pa'n largâ nha Mai, el ca triste comâ dor de'n bai pa'n largâ nha Amor.

No cantâ co água na ôjo; no bajâ co alma de nôjo: hora triste de partida é hora de perdê bida.

Quem que ficâ, ca ta bai: quem que ca bai, ca ta bem: força que pincha'n pa'n bai, é bo, esperança de bem!

Ó bai, ó bai, ja bo triste! Ouro de mar, ja bo caro! Ó bem, ó bem, ja bo doce! Dia de bem, ja bo claro!

Ambos os textos relatam uma realidade social bastante desfavorecida e, de certa maneira, miserável. E também em ambos textos, o autor escreve na primeira pessoa. Esta apresentação das duas 'estórias' vistas pelo narrador de forma autodiegética permite-nos retirar algumas ilações. O texto a), por exemplo, retrata a realidade factual de maneira pormenorizada, usando uma linguagem cuidada, muito além da mera descrição jornalística, chegando mesmo a tocar - se bem que muito levemente - a poesia. Expressões como "o pano preto com que 
envolvia a mágoa da sua saudade» e "morrer na sua terra sob o olhar manso da mulher e dos filhos" não podem não soar como críticas ferozes à administração despreocupada dos governadores de Cabo Verde, e ao mesmo tempo, não podem deixar de se manifestar ao leitor como uma fraseologia eufemística, que recusa a quase violência de uma linguagem nua e crua que o jornalismo hodierno virá a usar. Eufemística, dizíamos, para chamar a atenção para esta figura de estilo, que consegue mascarar perfeitamente aquilo que por vezes é doloroso para o leitor. E Tavares é consciente do alcance das suas palavras. Embora escreva com um estilo solene, a mensagem não é dirigida apenas aos leitores cultos e/ou autoridades de Cabo Verde, ela pretende atingir ouvidos mais longínquos, como os da Metrópole. Tavares sabe que muitas vezes os factos chegam até nós, mas sabe também que por vezes é preciso sermos interrogados por eles para poder abrir os olhos. "Perguntou-me»: isto é, ao Autor, a nós, a todo e qualquer indivíduo disposto a deixar-se tocar pela realidade.

É manifestamente evidente a ausência da língua crioula no artigo de jornal. Contudo, tem uma razão de ser e as suas motivações são claras. Tavares decide não redigir o artigo em crioulo, embora fosse um cultor e defensor daquela língua. Aliás, no jornal $O$ Manduco (mas vejase também o artigo "Língua de pretos» de 1924, in Monteiro 1997: 218219) afirmava que "[...] o crioulo merece ser estudado e conservado graficamente como elemento de filologian: p. 219).

Se partirmos do princípio de que todo o texto visa um certo tipo de destinatário (Osimo 1998: 2-11) e veicula um certo tipo de informação, também esta direccionada para um certo tipo de receptor, um artigo de jornal, obviamente, não foge a este esquema.

No século XIX tal tipo de intervenção dirigia-se principalmente às camadas sociais mais cultas, a saber, às elites alfabetizadas. Como a 'infância' (Pires Laranjeira 1995: 180)³ do Liceu-Seminário da ilha de

\footnotetext{
3 Foi criado em 1866 e durou até 1928, contribuindo para o surgimento de um número letrados igual ou superior aos angolanos. Em 1877, criou-se a imprensa periódica não oficial. D.A. Duarte (1998: 157) refere: «Reconhecendo, embora, todos os
} 
São Nicolau ainda produzia poucos intelectuais, claramente nem toda a população a ele tinha acesso. Portanto, com os artigos de jornal, Tavares podia aceder apenas a essa elite e, por conseguinte, esperar que as suas mensagens chegassem até ela; porque, nas palavras de Brito-Semedo (2006: 22), "[...] a imprensa constitui mesmo um acervo, pois possibilita desenhar uma radiografia da evolução ideológica dessa sociedade e obter a visão do mundo e de si própria que os seus membros tiveram nas diferentes épocas». Por esse motivo, o uso da língua portuguesa é, pois, necessário, principalmente porque o crioulo ainda não fora plena e devidamente aperfeiçoado na escrita. Mas ao mesmo tempo que é condição necessária para aceder aos leitores letrados, ela não é suficiente para alcançar todos os caboverdianos. Só o crioulo, através da música que lhe é 'congénere', digamos assim, pode chegar a toda a população, quer alfabetizada, quer não. Vejamos por isso o texto b).

Neste texto detectamos imediatamente o uso de uma palavra utilizada no texto a): mágua. No primeiro caso, a mágoa concernia ao luto pelo marido; no segundo, à partida do poeta para terra estrangeira. Em ambos os casos, a mágoa representa uma dor pela ausência de um ente querido, ausência essa que se pode transformar em morte: "sâ tâ matam nha bida = I 2 " "é hora de perdê bida $=$ III 4 ".

Mas não só este exemplo pode ser encontrado no texto. O poeta é ele mesmo obrigado a partir, para poder voltar, significando o regresso uma nova vida para os familiares abandonados: "é'n bai, 'n tornâ bem = I 4" "força que pincha'n pa'n bai, // é bo, esperança de bem! = IV 3-4". Também os versos que desenham as lágrimas e a tristeza que a separação provoca se encontram presentes nos dois textos: "No cantâ co água na ôjo; // no bajâ co alma de nôjo = III 1-2" e "olhos rasos de água,

benefícios que o ensino e, nomeadamente, a instrução ministrada pelo SeminárioLiceu, criado em 1866, trouxeram ao punhado de cabo-verdianos que a ele tiveram acesso, não se pode deixar de constatar os malefícios que a inferiorização e a marginalização do crioulo acarretaram para a sociedade cabo-verdiana, que, assim, se encontrou dividida em duas classes: a dos que falavam e escreviam o português (uma minoria) e a dos que não o falavam e, sobretudo, não o escreviam (uma significativa maioria)". 
voz trémula a cortar o coração". Em suma, a temática partilhada pelas duas línguas abraça os dois pontos contrastantes da realidade caboverdiana: a que lê e a que directamente sente. Deste ponto de vista, podemos dizer que o crioulo foi, com maestria, utilizado por Tavares para contar a mesma 'estória', uma história de dor, de saudade, de amor, de esperança e de morte. Temas muito actuais, mas não por acaso citados logo ao início do artigo, onde se diz que aquela viúva "talvez nos pudesse contar as dores e os cuidados duma comprida geração de trabalhadores do mar».

O mar fora e continua sendo aquele porto de partida, aquele porto de chegada e aquele meio através do qual se podia partir para regressar. Nunca um elemento se pôde representar de forma tão ambígua e contrastante ao mesmo tempo. Sem o mar a língua crioula não poderia ter encontrado tantos signos eficazes da sua criatividade e, ao mesmo tempo, da sua dor (Fernandes, 2004) ${ }^{4}$. Ao reescrever a interrogação da pobre mulher, viúva com seis filhos, em forma de morna, portanto, utilizando a língua crioula e não a portuguesa, Tavares conseguiu transportar a mesma mensagem veiculada no artigo a quem a esse artigo não podia aceder. Mas não pôde ser através da escrita, essa veio mais tarde, dado que a morna citada e publicada é de uma edição póstuma (1932). Essa mensagem teve que ser transportada através da música (Rodrigues \& Lobo, 1996).

Para oferecer ao povo caboverdiano a possibilidade de ver a sua língua valorizada, Tavares preferiu escrever aquilo que o seu povo sentia através do único modo que naquela época ele possuía para o exteriorizar: a música, a morna. A morna é assim o meio pelo qual o autor conseguiu levar a cultura popular do caboverdiano à camada letrada, grafando-a ao mesmo tempo com uma escrita. Embora se trate de uma escrita ainda não definitiva, vale certamente pela tentativa e pelo esforço de sistematizar o crioulo em cânones gramaticais. Não

\footnotetext{
$4 \mathrm{O}$ retrato do baleeiro é um elo que encadeia outras realidades insulares, como a açoriana, e também nela encontramos uma literatura de partida-regresso bastante eficaz quanto à caracterização das suas gerações e problemáticas sociais.
} 
sendo porém um linguista, por vezes a sua escolha não torna clara a distância que uma ou outra palavra tem do português, chegando por vezes a "falsificar" o espírito original da língua crioula. De resto, trata-se apenas de uma válida transcrição unidireccional oralidade-escrita ${ }^{5}$, e não de estudos linguísticos sobre a língua caboverdiana. De qualquer maneira, é mister não esquecer que as mornas de Eugénio Tavares foram as linhas de fuga de um desenho muito mais delineado, mas muito menos recalcado, do uso do crioulo caboverdiano.

É bastante perspicaz, e merece ser referida, a notação de Teixeira de Sousa quanto à forma na produção caboverdiana nos primeiros anos do século XX. Afirma ele que "Os poetas de antanho [...] cantavam estados de alma, com versos metrificados, rimados, com perfumes e cores inexistentes nas pobres ilhas» (Laban 1992: 164). Porém, o mesmo Teixeira de Sousa reconhece que Tavares, e como veremos adiante, também Pedro Cardoso, fugiam a esse estilo quanto à utilização do crioulo. Discordamos, no entanto, que o mesmo possa ser dito em relação à língua portuguesa. Como tentámos demonstrar, há quase que um nivelamento entre as duas línguas quanto à forma da composição. Pensamos que Tavares e Cardoso tentaram usar as duas línguas tendo em consideração o escopo para o qual viriam a ser utilizadas, e assim escolhiam ou o crioulo ou o português. Não se pode, contudo, negar que haja uma certa intenção, por parte de Tavares, de assemelhar a sua escrita em português aos modelos da literatura portuguesa, mas isso é óbvio e, diríamos até, natural.

Discordamos também em parte da afirmação radical de $M$. Ferreira (Laban 1992: 104), quando este diz que durante o século XIX e primeiras décadas do $\mathrm{xx}$ a literatura que se produz é uma literatura desenraizada, uma literatura influenciada pelo romantismo e pelo simbolismo que nada cria de verdadeiramente original, embora com interesse do ponto de vista estético. Tal característica justifica-se pela

\footnotetext{
5 Como diz M. Ferreira em resposta à pergunta de M. Laban: "Os povos africanos, e o cabo-verdiano mantém essa característica, são povos da comunicação oral [itálico meu], e então realizam-se muito no convívio, nas relações pessoais, nas relações familiares, de amigos, nos bailes, nas festas" (Laban 1992, p. 146).
} 
necessidade de estabelecer uma conexão, um laço infrangivel com a metrópole. Afirma ainda M. Ferreira que apesar desse seu desenraizarse, encontram-se nela indícios de preocupações pela realidade social do caboverdiano, embora muito timidamente e de um ponto de vista naturalista. Ora, realmente há tentativas de religação à Metrópole, mas são justificadas, dado que os primeiros escritores caboverdianos não professavam um espírito de independência ${ }^{6}$ da colónia. Com efeito, não existe ainda um percurso mental virado para a separação total da Metrópole, mas apenas o de indicação e detecção de problemas. Na realidade, esse espírito aparece juntamente com o nascimento do fascismo em Portugal. Orlanda Amarílis afirma que "[...] não foi por acaso que em 23 de Abril de 1936 é criado o campo de concentração no Tarrafal, na ilha de Santiago, na mesma época do nascimento de Claridade» (Laban 1992: 272).

Juntamente com Eugénio Tavares gostaríamos de reflectir brevemente sobre a figura de José Lopes, o qual opera uma espécie de 'retrocesso' na poesia caboverdiana.

O epíteto, aparentemente negativo, não pretende denegrir a figura de José Lopes, que fora um exímio conhecedor e 'manuseador' da língua portuguesa. A particularidade deste autor é precisamente a da sua utilização excepcional da língua portuguesa. José Lopes foi autor de muitas poesias e folhetos, e todos eles em português. A recolha de M.

$6 \mathrm{Na}$ verdade, o problema da independência nunca se coloca na literatura caboverdiana senão em meados dos anos '50. Os autores nascidos no século XIX têm uma visão ambígua, ou melhor, diluída do "problema" pátria. $\mathrm{Na}$ poesia, principalmente, o problema da pátria é posto com muita frequência, a pátria são todas as ilhas de Cabo Verde; às vezes, uma só, por vezes um pedaço de ilha, onde os autores viveram a sua infância... outras vezes é Portugal. Há uma mistura contínua de substratos originários. Porquê? Segundo M. Ferreira porque são homens educados por uma ideologia trazida pelo colonizador, que cobre todos os âmbitos do saber, desde a literatura, à arte, à crítica, etc. São também produtos de uma profunda aculturação e mestiçagem, e portanto muito próximos da cultura portuguesa. Sentem a necessidade de se fixarem a alguma coisa que aponte para uma origem, sobretudo uma norma. Mas, por outro lado, são precisamente fruto, filhos, de uma mestiçagem, que comem cachupa, cuscuz, amam a morna e descobrem em Cabo Verde a terra, isto é, a mãe de tudo aquilo que os circunda (Laban 1992: 110 e 112). Um verdadeiro complexo de Édipo que acaba por aflorar definitivamente como parricídio e com a independência de Cabo Verde. 
Ferreira (1989: 147) traz um exemplar das suas poesias, apenas a título informativo.

Nascido em 1872 (faleceu em 1962), Lopes teve acesso aos ensinamentos proporcionados pelo Liceu-Seminário e, por consequência, também à sua biblioteca. Com efeito, em relação à obra de divulgação de Tavares, José Lopes parece cumprir uma espécie de regresso ao estilo áulico da poesia portuguesa. Lopes foi um dos coautores das Hespérides (1930), um poema que pretendia dar uma origem mito-poética à descoberta das ilhas de Cabo Verde, onde, segundo a Antiguidade clássica, teria existido um continente no Atlântico a que se teria dado o nome de Continente Hespério; e as ilhas de Cabo Verde seriam então as ilhas arsinárias, de Cabo Arsinário, nome antigo do Cabo Verde continental, recuperado da obra de Estrabão e a partir da famosa lenda da Atlântida criada por Platão, no Timeu e no Crítias. Assim, os poetas teriam criado o mito poético para escaparem idealmente à limitação da pátria portuguesa, exterior ao sentimento ou desejo de uma pátria interna, intima, simbolicamente representada pela lenda da Atlântida7. E ao tentar dar essa origem mito-poética às ilhas, Lopes pretenderia retomar o estilo de Camões, porque mais próximo da sua realidade, mas também o de Virgílio e o de Homero. Há contudo um vazio factual na escolha do estilo camoniano, porque a estrutura utilizada foge à realidade caboverdiana. Muito mais próximo de uma verdadeira criação literária plenamente caboverdiana está Tavares, ao servir-se do crioulo como forma de sistematização da sua 'matéria cultural'.

Também M. Ferreira partilha desta hipótese ao dizer que:

Esse recuo aos tempos míticos, essa fuga para a hipotética origem de CaboVerde, não é mais do que a necessidade de exprimir textualmente uma identidade comum e original que eles [José Lopes e Pedro Cardoso] não encontrariam em relação a

7 Cf. Pires Laranjeira 1995: 181. Segundo o autor, este movimento pertenceria ao segundo período (movimento "hesperitano" ou "arsinário") dos seis em que dividiu a literatura caboverdiana. Para uma divisão diferente, $c f$. Margarido 1980; Moser \& Ferreira 1983. 
Portugal. Era a origem comum territorial, histórica e miticamente cultural (Laban 1992: 103-104).

Não se pode negar, porém, que as composições de Lopes não sejam excelentes do ponto de vista da métrica. O que é importante realçar acerca da figura deste poeta é exactamente o facto de ele ser o 'negativo' da fotografia da realidade crioula caboverdiana. Não obstante, continua sendo um autor de cultura exímia e um aceso defensor do conhecimento profundo da cultura outra para a criação da própria realidade cultural.

Ora, com Pedro Cardoso (1890-1942) temos uma espécie de inversão de marcha. O uso que José Lopes fazia da língua portuguesa está nos antípodas, relativamente à consolidação da literatura caboverdiana de inícios do século Xx. Com efeito, Pedro Cardoso - se bem que co-autor do poema Hespérides - encontra-se numa linha de pensamento completamente oposta à de J. Lopes. In primis, Cardoso assim se exprimia em conferência acerca do crioulo de Cabo Verde, no então Teatro Virgínia Vitorino ${ }^{8}$, na cidade da Praia, em 1933:

Todos aprendem a língua estrangeira tendo por instrumento a língua materna; saibam também os professores de instrução primária servir-se do crioulo como veículo para mais rápido e profícuo ensino das matérias do programa a cumprir, principalmente do português.

São claros os objectivos programático e didáctico com os quais Cardoso pretende instrumentalizar a língua crioula. Sobretudo porque o autor vê na língua caboverdiana a revalorização das tradições, bem como o nivelamento da língua materna a verdadeira língua oficial. Por esse motivo, o uso alternado da língua portuguesa e crioula, ou por

\footnotetext{
8 Este teatro nasceu com o nome de "Theatro Africano" em 1868, e foi constituído por filhos das ilhas. Ao que tudo indica, o seu propósito seria o de fazer frente a outro teatro (Theatro de Dona Maria Pia de Saboya) criado por oficiais do reino em destacamento no arquipélago. Apesar de ter sido hipotecado em 1897, o Theatro Africano teve longa vida e mudaria de nome para "Teatro Virginia Vitorino" em 1933, em homenagem à poetisa e teatróloga portuguesa (1895-1968), muito em voga naqueles anos (Brito-Semedo 2006: 127-130).
} 
vezes até mista, visa a integração e a simbiose das duas facetas da cultura caboverdiana.

Vejamos, a este propósito, duas poesias. A primeira (indicada com a letra a) ${ }^{9}$ inteiramente escrita em crioulo caboverdiano, embora com um alfabeto ainda não definitivo e sujeito a modificações. A segunda (indicada com a letra b), em texto mestiço, no qual aparecem as duas línguas usadas de maneira a criar um unum. Dois exemplos em aparência contraditórios, mas que podemos dizer ligados elipticamente.

a)

Coitado quem dixâ sê terra sêl dixâ nél sê coraçom; êl embarcâ pa terra longe sim sabê si al birâ, ó nam!

Coitado quem p'ês mar de Cristo cubiça têm chumá-1, lebá, pôs canto bês tem conticedo muto que bai ca boltâ má!

Coitado quem nim ta drumi sê coraçam ta descançâ: pa punde êl bai voz de sodade na obido 'stá-l' sá ta chorâ!

Coitado quem na terra estranho, sim má, sim pá, sim jaraçôm, si êl dijijâ bêm pa sê terra ca achâ ninguêm padá-l' de môm!

b)

Triste descamba o sol na curva do horizonte nas vagas mergulhando a luminosa fronte.

Como a terra fica triste quando o sol se esconde além! Assim minha alma entristece quando me deixas, meu bem! Dos montes vem tombando a sombra, e os passarinhos ao tépido conchego acolhem-se dos ninhos.

Há na noite mais cerrada sempre uma réstia de luz: no auge da mor amargura sempre a esperança transluz.

E de volta da monda ou da fonte, ligeiras,

9 "Crioulo do Fogo - IV", in: Folclore caboverdeano, Porto, Edições Maranus, 1933. Usámos a edição de Ferreira 1997: 293. 
mornas passam cantando as crioulas trigueiras.

Manso, manso, raparigas, cantai do amor a canção!

Quero ouvir em vossos lábios

palpitar o coração.

Mornas passam cantando as frescas camponesas

e põem-se a escutar as aves nas devesas.

Cantai, mas devagarinho,

cantai p'ra eu adormecer!

Ao som das vossas cantigas

embalai-me até morrer!

A noite desce e envolve o céu, a terra e o mar.

A lua que surgiu das montanhas além,

parece que se queda enlevada a escutar...

Que esplêndida garganta! Escutemos também.

Canal de Brava soluçâm sodade,

e mar de golfo soluçâm cuidado!

Ai djam drumi sono tam tromentado

só ta sunhâ co prigo de nha bida!

O pasadinha de pena azul,

imprestâm bu pena ma bu tintero!

Pam fazê um carta pa quêl ingrato

que imbarcâ, êl bai sim dispedi.

Oh! que fé, esperança mam têm na-êl, tornâ screbê êl ca mandam mantenha!

Si êl bem, êl ca atchâm, pêl ca stranhâ, pamó mi ê nobo mta brincâ tambê!...

Ao longe doce, branda e langorosamente expiraram os sons da saudosa canção.

A brisa suspirou no milharal virente

num longo murmurinho e funda comoção.

Num halo de esplendor divino e radiante, sobre a montanha a lua elevava-se ovante como uma águia real que a nívea asa espalmada 158-159).

se arremessasse aos céus numa louca arrancada! (Ferreira 1989:

O primeiro texto contém algumas incógnitas a nível linguístico.

Por exemplo, o autor grafa sempre com o acento circunflexo vogais cuja abertura fonética é mínima ou quase inexistente. Tal sistema, porém, cria ambiguidade em palavras já existentes no português, como é o caso da forma verbal "têm", no segundo verso da segunda estrofe. A língua portuguesa usa esta forma verbal acentuada (que indica a terceira pessoa do plural) para a distinguir da terceira pessoa do singular do mesmo verbo ter e, desta forma, a utilização de um acento circunflexo não torna clara a fonética do termo crioulo. No texto de Cardoso, porém, 
estamos a falar de um "vir" e não de um "ter" ("a cobiça vem chamá-lo, levá-lo»), mas só o contexto e o conhecimento da língua caboverdiana são capazes de desatar este nó.

Esta notação demonstra apenas que não havia um verdadeiro debruçar-se sobre a escrita do crioulo. Mesmo defendendo acerrimamente a utilização dessa língua, Cardoso não foi capaz de resolver problemas como este. Mas muito provavelmente porque não era esse o seu principal escopo, nem tão-pouco o colocava como problema a ser resolvido. Encontramo-nos, com efeito, num momento histórico em que a experimentação do crioulo escrito é mais profícua do que a tematização da sua gramática. Esse trabalho deve ser deixado aos vindouros, àqueles para quem a realidade escrita representa já um laboratório onde poder observar, investigar e trabalhar. Por conseguinte, o texto b) apresenta-se como um texto precioso, quer do ponto de vista literário, quer linguístico. De facto, no segundo texto encontramos a simbiose das duas culturas em acto. Em potência encontramos apenas a sua interpretação. Para quê escrever nas duas línguas? Ao contrário do que afirma Gabriel Mariano (Laban 1992: 326) que ao escrever em português, os escritores caboverdianos são fotocópias dos poetas portugueses, pensamos que uma 'reprodução facsímile' das obras portuguesas não ocorra a 100\%, nem sequer a 50\%. Há demasiada interferência para que as duas realidades se possam dizer especulares. Estamos, porém, de acordo com Mariano quando este afirma que

Escrevendo em crioulo dão-se duas coisas. Primeiro aspecto: uma identificação através da língua crioula, uma identificação com o seu próprio ambiente [...] uma identificação do poeta com a sua própria terra (Laban 1992: 326).

O texto b) de P. Cardoso atesta mesmo isso. Não obstante a maioria das suas publicações seja em português ${ }^{10}$, o autor utiliza por

10 Cadernos luso-africanos, 3 vols., por exemplo, contêm certamente textos em crioulo. O $1 .^{\circ}$ volume é de 1941 e chama-se É mi que é Ilha'r Fogo; o $2 .^{\circ}$, Ritmos de morna, é de 
várias vezes o crioulo nos seus textos. Podemos com isso supor que pretendia contribuir para que se mostrasse que Cabo Verde tinha uma personalidade regional autónoma e diferenciada? Talvez sim, ou talvez não. O importante é demonstrar e realçar a linha de passagem entre os dois registos linguísticos, sem que por isso se dê a anulação de ambos ou a sobreposição de um ao outro.

O segundo texto começa com a descrição da paisagem natural caboverdiana, mas não cantando «estados de alma, com versos metrificados, rimados, com perfumes e cores inexistentes nas pobres ilhas", como afirmara Teixeira de Sousa supra. Com efeito, o sol realmente se põe sobre o mar e dos montes se forma a sombra que cobre as ilhas ( $c f$. a primeira e a segunda estrofes). As rimas são emparelhadas (p. e., horizonte/fronte) umas vezes, e alternadas outras (p. e., além/bem) ${ }^{11}$, e em dois casos, interpoladas (p. e., langorosamente/canção/virente/comoção).

A poesia é bastante complexa, sobretudo porque emprega duas tipologias de divisão de estrofes e também porque se serve de uma métrica assimétrica. In primis, as estrofes iniciais são agrupadas em estrofes de dois e de quatro versos intercaladamente, por um lado, e depois num bloco compacto de doze versos, por outro (que poderia ser dividido em três estrofes de quatro), seguidos novamente por duas estrofes de quatro versos cada uma. In secundis, no bloco de doze versos - os versos dedicados ao crioulo - encontramos apenas uma rima (cuidado/tromentado) e uma só assonância: mantenha/stranhâ.

Se quiséssemos reproduzir o esquema métrico do texto b), teríamos algo do tipo:

$a a / / a b c b / / a a / / a b c b / / a a / / a b c b / / a a / / a b c b / / a b a b / / a b$ bcdefghijk//abab//aabb 
Porque é importante debruçarmo-nos um instante sobre a métrica desta poesia? Em primeiro lugar, para excluir P. Cardoso da classe dos fotocopiadores da literatura portuguesa e depois para justificar a tese de uma simbiose linguística existente já nos anos '30.

Com efeito, a estrutura métrica da poesia demonstra como as rimas cadenciam a descrição da realidade caboverdiana vista no seu dia-a-dia. Temos um espectador - o poeta - que observa o arco dos eventos de um dia comum como o que está a ser percepcionado: o sol põe-se, mergulhando os seus raios no mar, desaparecendo por completo; as montanhas escurecem a terra. Há uma intersecção desta percepção sensorial como sentimento do autor em relação à partida da bem amada (e aqui, o esquema em nada foge aos cânones de qualquer poesia europeia, mas não subtrai, por isso, à crioula a sua originalidade), partida que deixa na boca um sabor a tristeza e a abandono. E neste momento, mesmo os mais pequenos seres vivos sentem o desejo de regressar a casa ("[...] e os passarinhos // ao tépido conchego acolhem-se dos ninhos»). Mas mesmo num dia de tristeza, como num dia de escuridão profunda, há sempre algo que transpira alegria, como o fio de luz que corta o breu da noite.

Ao sentir estas contradições dentro de si, o poeta vê-se novamente catapultado e direccionado para a realidade que o circunda e da qual não pode fugir, se verdadeiramente pretende colher na sua essência a caboverdianidade. Trata-se daquele rasgo de realismo dado pela entrada em cena das crioulas que trazem nos lábios as cantigas da monda, as músicas de trabalho ${ }^{12}$. Também estas pinceladas naturalistas se podem identificar na literatura europeia, especialmente na portuguesa, mas nem por isso deixam de contribuir para a efectiva distinção entre aquela literatura e a caboverdiana. A distinção é dada exactamente por aquele factor que contrapõe as duas realidades: o crioulo, mas não só o crioulo; o crioulo em forma de morna. A morna recupera assim o seu

\footnotetext{
12 Para ter uma ideia do tipo de músicas cantadas pelos mondadores e marinheiros, veja-se o óptimo trabalho de Oswaldo Osório s/d. A obra traz a transcrição das músicas e também um vinil com as vozes dos informantes.
} 
lugar esquecido por José Lopes, por exemplo. Não havia, como vimos, nenhum acenar a formas de tradição explicitamente oral nas suas poesias.

No breve flash que Cardoso faz da sucessão dos acontecimentos, a figura das mondadeiras desempenha um lugar fundamental na economia do texto. Num momento de tristeza há algo que reluz e esse algo é dado pela música que acompanha as mondadeiras. O poeta deseja, bem como toda a natureza circundante (as aves, a lua, por exemplo), almeja ouvir aquilo que as raparigas trigueiras têm para dizer, e só podem dizê-lo numa língua. O crioulo oferece aquele momento de pausa ("Manso, manso»; "devagarinho"; "cantai p'ra eu adormecer!»; "embalai-me») que o decorrer das vissicitudes diárias do poeta não lhe pode conceder. Recordamos que se vivia um momento em que a língua portuguesa imperava e era obrigatória nas escolas ${ }^{13}$. Por esse motivo, qualquer poeta se concentrava em primeiro lugar sobre a composição em português. Estes momentos de pausa de que se socorre o autor e que lhe são necessários justificam o uso recorrente do adjectivo "manso" e do advérbio "devagarinho".

Em coro uníssono se juntam as 'orelhas' para ouvir o que as mondadeiras têm para contar/cantar ("Escutemos"). As mondadeiras cantam/contam dos seus amores e desgostos, da partida dos amados que não regressam e não respondem aos seus apelos; narram daqueles que partem para deixar saudade. Nas suas palavras há a menção a um ouvinte que só em algumas ilhas de Cabo Verde existe: a passarinha ${ }^{14}$. O pássaro que oferece a sua pena azul para que com ela a mondadeira possa escrever uma carta ao amado.

\footnotetext{
13 Refere Luís Romano que "Na escola era obrigatório o Português, sob pena de castigo corporal; quem fosse surpreendido pelo Professor, na sala de aula, desobedecendo à ordem, já sabia quantas palmatoadas iria receber» (Laban 1992: 226). A utilização obrigatória do português aparece relativamente tarde na história das ilhas. D.A. Duarte afirma que «Em Cabo Verde, por exemplo, o português só começou a ser falado nas relações não oficiais, e por uma pequena minoria, na segunda metade do século XIX. Testemunhos de vários portugueses chegados ao arquipélago deixam ver que, até meados do século passado, o crioulo era, praticamente, a única língua de comunicação nas Ilhas" (1998: 123-124).

14 Trata-se da Halcyon leucocephala. Mas vide Lang 2002: 549; e MASSA 2001: 117.
} 
Como se pôde depreender das sugestões oferecidas pela hermenêutica do texto, há uma tenção/tensão do autor para a integração de duas realidades que por largos séculos viveram em separação cultural. Pedro Cardoso pretendia elevar o crioulo, como já o pretendera Tavares, por sua vez, à forma de escrita literária e não meramente oral, mostrando com isso a possibilidade de se investir na sua consolidação linguística e, por conseguinte, na consolidação de uma verdadeira literatura caboverdiana (Teixeira de Sousa 1958: 2-8). Dessa forma, podemos considerá-lo também um propulsor da criação de um estilo literário ainda muito embrional, mas que permitiu a evolução de muitas outras tentativas laboratoriais de aperfeiçoamento da língua caboverdiana escrita.

\section{Referências bibliográficas}

BRITO-SEMEDO, Manuel. A construção da identidade nacional. Análise da Imprensa entre 1877 e 1975, Praia, Instituto da Biblioteca Nacional e do Livro, 2006.

DUARTE, Dulce Almada. Bilinguismo ou diglossia?, Praia, Spleen Edições, 1998. FERNANDES, Margarida. Hora di bai. Os Cabo-Verdianos e a Morte: uma abordagem antropológica através da literatura de ficção, Águeda, Nova Vega, 2004.

FERREIRA, Manuel (org.). 50 poetas africanos, Lisboa, Plátano Editora, 1989.

FErReIrA, Manuel (org.), No reino de Caliban, $4^{a}$ ed. vol. I, Lisboa, Plátano Editora, 1997.

Gomes DE PINA, Maria da Graça. Introduzione. In TAVARES, Eugénio. Mornas. Canzoni creole, Napoli, Guida, 2005, p. 1-21.

LABAN, Michel (org). Cabo Verde - encontro com escritores, vol. I, Porto, Fundação Eng. António de Almeida, 1992.

LANG, Jürgen et al., Dicionário do Crioulo da Ilha de Santiago (Cabo Verde)/ Wörterbuch des Kreols der Insel Santiago (Kapverde), Tübingen, Gunter Narr Verlag, 2002.

MARGARIDO, Alfredo. Estudos sobre literaturas das nações africanas de língua portuguesa, Lisboa, A Regra do Jogo, 1980.

MASSA. Jean-Michel (org.) Dictionnaire encyclopedique et bilingue du Cap-Vert, Rennes, EDPAL, 2001.

MONTEIRO, Félix (org.). Eugénio Tavares pelos jornais..., Praia, Instituto Caboverdeano do Livro e do Disco, 1997.

Moser, Gerald-FERREIRA, Manuel (orgs.). Bibliografia das Literaturas africanas de expressão portuguesa, Lisboa, Imprensa Nacional-Casa da Moeda, 1983.

OsIMO, Bruno. Manuale del traduttore, Milano, Hoepli, 1998.

OsÓRIO, Oswaldo (org.). Cantigas de trabalho. Tradições orais de Cabo Verde, Lisboa, Plátano Editora, s/d. 
PIRES LARANJEIRA, José. Literaturas africanas de expressão portuguesa, Lisboa, Universidade Aberta, 1995.

RoDRIGUES, Moacyr-LoBo, Isabel (eds.). A morna na literatura tradicional: fonte para o estudo histórico-literário e a sua repercussão na sociedade, Praia, Instituto Caboverdiano do Livro e do Disco, 1996.

TAVARES, Eugénio. Mornas - cantigas crioulas, Lisboa, J. Rodrigues \& C. ${ }^{\text {a }}$ Editores, 1932.

TeIXeIrA DE SousA, Henrique. Cabo Verde e a sua gente. In Cabo Verde Boletim de Propaganda e Informação, Praia; Imprensa Nacional: ano IX (108): 2-8, 1958. 